\title{
AN INTRODUCTION TO THE ECONOMY OF THE KNOWLEDGE SOCIETY
}

Paul A. David

Dominique Foray

2001-041

December 2001

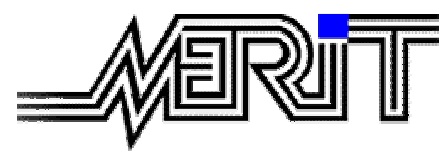

MERIT - Maastricht Economic Research Institute on Innovation and Technology PO Box 616 6200 MD Maastricht

The Netherlands

$T:+31433883875$

F: +31433884905

http://meritbbs.unimaas.nl e-mail:secr-merit@merit.unimaas.nl

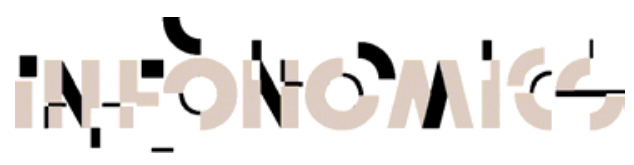

International Institute of Infonomics

PO Box 2606

6401 DC Heerlen

The Netherlands

$T:+31455707690$

F: +31455706262

http://www.infonomics.nl

e-mail: secr@infonomics.nl 



\title{
An Introduction to the Economy of the Knowledge Society
}

\author{
By
}

\section{Paul A. David and Dominique Foray}

First English draft: 13 September 2001

This version: 5 December 2001

This article elaborates upon the authors' introduction to the

Special issue of the UNESCO

International Social Science Journal, $\mathrm{n}^{\circ} 171$, on

"The Knowledge Society,"

prepared under the guest-editorship of Dominique Foray, forthcoming from Basil Blackwell Ltd. in March 2002

\section{Acknowledgements}

P. A. David gratefully acknowledges the support that his work on this paper received under a grant from the Dutch Ministry of Economic Affairs to the International Institute on Infonomics for its IRIS Project, on Intellectual Property Rights in the Information Society. D. Foray expresses his appreciation of the supportive research environment of CERI/OECD, without implicating the latter organization in the views presented herein.

Contact Author: Prof. P. A. David, All Souls College, Oxford, OX1 4AL, U.K.

Tel: 44+(0)1865+279313; Fax: 44+(0)1865+279299;

E-mail: paul.david@economics.ox.ac.uk,pad@leland.stanford.edu 


\title{
An introduction to the economy of the knowledge society
}

\author{
Paul A. David and Dominique Foray
}

\begin{abstract}
This introductory article reviews the main themes relating to the development of new knowledge-based economies. After placing their emergence in historical perspective and proposing a theoretical framework which distinguishes knowledge from information, the authors characterize the specific nature of such economies. They go on to deal with some of the major issues concerning the new skills and abilities required for integration into the knowledge-based economy; the new geography that is taking shape (where physical distance ceases to be such an influential constraint); the conditions governing access to both information and knowledge, not least for developing countries; the uneven development of scientific, technological (including organizational) knowledge across different sectors of activity; problems concerning intellectual property rights and the privatization of knowledge; and the issues of trust, memory and the fragmentation of knowledge.
\end{abstract}

\section{Biographical Notes}

Paul A. David is Professor of Economics, and Senior Fellow of the Stanford Institute for Economic Policy Research at Stanford University; he also is Senior Research Fellow of All Souls College, and Professor of Economics and Economic History in the University of Oxford. David is internationally recognized for his contributions to American economic history and the economics of science and technology, fields in which he has authored over 120 articles and contributions to books. Email: paul.david@economics.ox.ac.uk; pad@stanford.edu

Dominique Foray is a Director of Research at CNRS and Professor at the Institut pour le Management de la Recherche et de l'Innovation at Paris-Dauphine University. His work focuses on the characteristics and performance of knowledge-based economies. Email: dominique.foray@,oecd.org 


\title{
An introduction to the economy of the knowledge society
}

\author{
Paul A. David and Dominique Foray
}

\section{Historical perspective}

Knowledge has been at the heart of economic growth and the gradual rise in levels of social well-being since time immemorial ${ }^{1}$. The ability to invent and innovate, that is to create new knowledge and new ideas that are then embodied in products, processes and organizations, has always served to fuel development. And there have always been organizations and institutions capable of creating and disseminating knowledge: from the medieval guilds through to the large business corporations of the early twentieth century, from the Cistercian abbeys to the royal academies of science that began to emerge in the seventeenth century. "Knowledge-based economy", however, is a recently coined term. As such, its use is meant to signify a change form the economies of earlier periods, more a "sea-change" than a sharp discontinuity. This transformation can be analysed at a number of different levels.

\subsection{The acceleration of knowledge production}

The crux of the issue lies in the accelerating (and unprecedented) speed at which knowledge is created, accumulated and, most probably, depreciates in terms of economic relevance and value. This trend has reflected, inter alia, an intensified pace of scientific and technological progress. It has a host of ramifications and gives rise to many new challenges (see sections 5 and 6). But the discontinuity is not equally pronounced in every sector (see section 5.2). A new kind of organization is spearheading the phenomenon: knowledge-based communities, i.e. networks of individuals striving, first and foremost, to produce and circulate new knowledge and working for different, even rival, organizations. One sign that a knowledge-based economy is developing can be seen when such individuals penetrate conventional organizations to which their continuing attachment to an "external" knowledge-based community represents a valuable asset. As members of these communities develop their collective expertise, they become agents of change for the economy as a whole (see section 3).

\subsection{The rise of intangible capital at macroeconomic level}

Economic historians point out that nowadays disparities in the productivity and growth of different countries have far less to do with their abundance (or lack) of natural resources than with the capacity to improve the quality of human capital and factors of production: in other words, to create new knowledge and ideas and incorporate them in equipment and people.

A related characteristic of economic growth, that became increasingly evident from the early twentieth century onwards, is the growing relative importance of intangible capital in total productive wealth, and the rising relative share of GDP attributable to intangible capital (Abramovitz and David, 1996; Abramovitz and David, 2000). Intangible capital largely falls into two main categories: on the one hand, investment geared to the production and dissemination of knowledge (i.e. in training, education, $\mathrm{R} \& \mathrm{D}$, information and coordination); on the other, investment geared to sustaining the physical state of human capital (health expenditure). In the United States, the current value of the stock of intangible capital (devoted to knowledge creation and human capital) began to outweigh that of tangible capital (physical infrastructure and equipment, inventories, natural resources) at the end of the 1960s.

Recent work by OECD has helped produce stable categories of knowledge-related investment for given countries or sectors. Taking the simple yet highly restrictive measure of investment in research and development, public education and software, one can see that annual investment rates have grown strongly since the 1980s (at an average 
annual rate of $3 \%$ in the OECD countries). Investment structures, however, differ from one country to the next: Scandinavian countries, for instance, spend more on public education, while industrial investment (private-sector R\&D, software and information technology equipment) tops the list in the United States (OECD, 1999).

This basic underlying trend must not be allowed to obscure the growing importance of science and technology-related activities. Knowledge-based economies are not, of course, restricted to the realm of high technology, but science and technology do tend to be central to the new sectors giving momentum to the upward growth of the economy as a whole over the past few decades (pharmaceuticals and scientific instrumentation, information and communication technologies, aeronautics, new materials).

These developments are reflected in an ever-increasing proliferation of jobs in the production, processing and transfer of knowledge and information. This trend is not just confined to the high-technology and information and communication service sectors as it has gradually spread across the entire economy since first coming to light as early as in the 1970s. Society as a whole, then, is shifting to knowledge-intensive activities.

\subsection{Innovation is becoming the dominant activity, its sources ever-more varied}

Another reflection of the aforementioned "gear change" is the growing speed and intensity of innovation. There are two main ways in which breakthroughs come about: first, through formal research and development work off-line (i.e. "isolated" and "sheltered" from the regular production of goods and services); second, through learning online, where individuals learn by doing and, as a rule, can assess what they learn and hone their practices for what follows next. This can be an extremely potent form of knowledge production in many professions.
Significantly increasing investment in innovation (not least in R\&D) has sent the numbers of innovations appearing soaring, as evidenced not only by the volume of patents requested and approved (OECD, 1999), but also by the proliferation of new varieties of goods and services that has marked the trend toward "mass customization" (see David, 2000a). At the same time, practice-based learning environments appear to be broadening out from situations where Fordist divisions of labour in offices and factories reduced the individual's scope of activity and, hence, opportunity to learn. This, in turn, is fostering ever-greater possibilities for knowledge creation.

Meanwhile, the "need to innovate" is growing stronger as innovation comes closer to being the sole means to survive and prosper in highly competitive and globalized economies. It is not easy to distinguish between absolute novelties ("under the sun") and innovations that are new only to the companies that adopt them, or more complex adaptations of existing products or ideas to a new market. The fact remains that companies and society in general are spending more time and energy on producing and adjusting to change. ${ }^{2}$

Formal research may remain the cornerstone of knowledge production in many sectors (for the simple reason that it provides a more or less sheltered domain in which to carry out experiments that would not otherwise be possible in real life). But the knowledge production system is becoming more widely distributed across a host of new places and actors. More and more "innovators" tend to be appearing in unexpected situations: users as the source of innovation (von Hippel, 1988a), "lay people" involved in the production of scientific knowledge within such realms as health and the environment. ${ }^{3}$

\subsection{The revolution in instruments of knowledge}

The fourth level at which the "soft discontinuity" can be analysed concerns the major technological revolution that is taking place as we enter the digital age. It is a revolution of crucial importance in that it 
basically involves technologies for knowledge and information production and dissemination. These new technologies, which first emerged in the 1950s and then really took off with the advent of the Internet, have breathtaking potential. They enable remote access to information and the means of acquiring knowledge. In addition to transmitting written texts and other digitizable items (music, pictures), they also allow users to access and work upon knowledge systems from a distance (e.g. remote experimentation), to take distance-learning courses within the framework of interactive teacher-student relations (tele-education) and to have unbelievable quantities of information - a sort of universal library - available on their desktops.

Information technologies can affect knowledge creation in a number of different ways. For a start, the mere fact that one has the capacity to create such a wealth of information is truly revolutionary. Imagine how hard it was for people to obtain instruments of knowledge before the modern age. Apart from a handful of marvellous centres of intellectual life such as the ancient library of Alexandria, such facilities were few and far between. The great eleventh century thinker, Gerbert d'Aurillac, had a library containing no more than 20 books (although that was quite a lot in those days). Even in the somewhat less perilous times of a couple of decades ago, imagine what a laborious task it was for students to produce a round-up of the "state of the art" in a particular subject or discipline, and the uphill struggle involved in remaining abreast of the latest findings in their study field.

Development here has been a long, drawn-out process punctuated by the invention of the codex and the book (which took over from scrolls), the perfecting of paper, the book's transformation into a knowledge tool (indexes, tables, footnotes and endnotes), improvements in the productivity of copy-making (from the "industrial" organisation of the scriptorium through to the invention of the printing press), the proliferation of modern libraries and, finally, the advent of increasingly high-performance access and communication networks. Do new technologies signal an end to that evolution? Clearly not, for an enormous amount of progress remains to be made in such areas as information search systems. But this might almost be said to be the culmination of what the French medievalist Georges Duby once called the "relentless pursuit of instruments of knowledge" that has preoccupied humankind since the dark ages.

Second, information technologies enhance creative interaction not only among scholars and scientists but, equally, among product designers, suppliers and the end customers. The creation of virtual objects that can be modified ad infinitum and are instantly accessible to one and all, serves to facilitate collective work and learning. In that respect, the new possibilities that computers have opened up for numerical simulation represent another significant departure from prior experience.

Third, the new technologies enable the exploration and analysis of the contents of gigantic databases, which is in itself a potent means of knowledge enhancement (in natural, human and social sciences and management alike). Research stimulated by such possibilities has a strong influence in some areas of managerial work.

Finally, the above three ways in which information technologies affect knowledge creation can be combined in the development of large-scale decentralized systems for data gathering and calculation and the sharing of findings. Such extensive systems characterize the research being done these days in the fields of astronomy, oceanography and so on.

\subsection{Five years of the "new economy" -- viewed in historical perspective}

Now that the emergence of knowledge-based economies has been put into historical perspective, the new economy debate can only be viewed with a degree of amusement. It has focused on the possible need for a 
radical reform of macro-economics because the dominant tenets of that field appeared to have been surprised by the American economy's performance during the last half-decade of an entire millennium. Overall, this debate will mainly be remembered for the clash between the ultra-optimists and their relatively crude economic thinking, and the sceptical macroeconomists who, despite their usual rigour and prudence, have an extremely partial and truncated view of the impacts of new technologies (Gordon, 2000). Yet is not what the United States and, more recently, European and other Western countries have been experiencing just part of an accelerating transition to the knowledge-based economy, a process that began quite some time ago but which only started gathering momentum fairly recently owing to the slow maturation of the new, general-purpose technology of digital information processors and computer-mediated telecommunications (David, 1990, 2000, 2001a).

\section{Exploring the black box of "knowledge"}

Before going on to describe the workings of a knowledge-based economy, it is important to have a clear idea of exactly what it is that is passing through the electronic pipelines: knowledge, information or data? Something of each, actually. It all depends on the nature of the relationship between the senders and recipients.

\subsection{Knowledge and information}

A basic distinction should be drawn between knowledge and information. ${ }^{4}$ Knowledge - in whatever field - empowers its possessors with the capacity for intellectual or physical action. So what we mean by knowledge is fundamentally a matter of cognitive capability. Information, on the other hand, takes the shape of structured and formatted data that remain passive and inert until used by those with the knowledge needed to interpret and process them. The full meaning of this distinction becomes clear when one looks into the conditions governing the reproduction of knowledge and information.
While the cost of replicating information amounts to no more than the price of making copies (i.e. next to nothing thanks to modern technology), reproducing knowledge is a far more expensive process because some, indeed many, cognitive capabilities are not easy to articulate explicitly or to transfer to others. There are elements that therefore remain "tacit": "we know more than we can say" (Polanyi, 1967). ${ }^{5} \quad$ Knowledge reproduction has therefore long hinged on the "master-apprentice" system (where a young person's capacity is moulded by watching, listening and imitating) or on interpersonal transactions among members of the same profession or community of practice. These means of reproducing knowledge may remain at the heart of many professions and traditions, but they can easily fail to operate when social ties unravel, when contact is broken between older and younger generations and when professional communities lose their capacity to act in stabilizing, preserving and transmitting knowledge. In such cases, reproduction grinds to a halt and the knowledge in question is in imminent danger of being lost and forgotten.

\subsection{Codification of tacit knowledge}

On the other hand, knowledge may, be codified: so articulated and clarified that it can be expressed in a particular language and recorded on a particular medium. Codification involves the exteriorization of memory (Favereau, 1998). It hinges on a range of increasingly complex actions such as using a natural language to write a cooking recipe, applying industrial design techniques to draft a scale drawing of a piece of machinery, creating an expert system from the formalized rules of inference underlying the sequence of stages geared to problems and so on. As such, knowledge is detached from the individual and the memory and communication capacity created is made independent of human beings (as long as the medium upon which the knowledge is stored is safeguarded and the language in which it is expressed is remembered). With the emergence of codification, "the problem of memory ceases to dominate intellectual life" 
(Goody, 1977). Learning programmes are then produced that partially replace the person who holds and teaches knowledge. Goody (1977) notes that a written recipe can partially fill up the empty space created by the absence of the grandmother.

"Partially" is the key word here because for codification amounts to the process of reducing human knowledge to information, and in the course of such transformations some things almost certainly something will be altered, and, quite likely, other meanings will be lost. What is expressed and recorded, then, is not complete knowledge. It is a learning programme that helps to stabilize and reproduce knowledge. When a young technician receives a user's manual, he or she is not directly given knowledge on "how to run the machine". That said, the manual is helpful and will serve to reduce the costs of knowledge reproduction.

In many cases, when technicians have "learned to learn" and are dealing with a more or less standard machine, knowledge reproduction becomes almost instantaneous and assumes characteristics close to those of information reproduction. In more complex cases, however, the codified knowledge, while certainly useful, will only provide partial assistance. Knowledge reproduction will then occur through training, practice and simulation techniques (aircraft pilots, surgeons).

There is, it must be stressed, a second and, in our view, crucial function of codification. Codification consists in translating knowledge into symbolic representations so that it can be stored on a particular medium. This creates new cognitive potentialities that remain inconceivable so long as the knowledge is attached to individual human beings and, hence, only heard (when spoken) or seen (when put into practice) through interaction with those carriers. Inscribing (through writing, graphics, modelling, virtuality) makes it possible to examine and arrange knowledge in different ways and to isolate, classify and combine different components. This leads to the creation of new knowledge objects such as lists, tables, formulae, etc. These are fundamentally important in that they open up new cognitive possibilities (classification, taxonomy, tree networks, simulation) that can provide a framework for the rapid production of new knowledge (Goody, 1977). But they are only possible when people consider the matter of recording and, hence, the symbolic representation of their cognitive states. Advances in information technology-based recording methods are crucial here, for they allow representations of knowledge to progress from the so-called "pre-literate" stage (gestures and words) to the literate (writing and drawing) and then post-literate stages (modelling structured interactions).

Codification thus plays a central role in the knowledge economy because it serves to further memorization, communication and learning, and forms a sound basis for the creation of new knowledge objects.

\section{Knowledge-based communities as agents of economic change}

Knowledge-based activities emerge when people, supported by information and communication technologies, interact in concerted efforts to co-produce (i.e. create and exchange) new knowledge. Typically, this involves three main elements: a significant number of a community's members combine to produce and reproduce new knowledge (diffuse sources of innovation); the community creates a "public" space for exchanging and circulating the knowledge"; new information and communication technologies are intensively used to codify and transmit the new knowledge.

\subsection{Rachid and Rachel}

The following fable brings out the significance of the last of the above three components (the use of new technologies for knowledge codification and transmission). Let us compare the experiences of two scholars: Rachid, a seventeenth century astronomer from the beautiful town of Fez, and Rachel, an imaginary young engineering postdoctoral student working in a Stanford 
University laboratory in the late twentieth century.

Rachid invented a new telescope and wanted to transmit the details of his discovery to colleagues in Cordoba, Padua and Salamanca. This was an arduous task because this kind of knowledge had not yet been codified at the time and he had to copy all of his plans and notes by hand. Rachid then entrusted his precious documents to the northbound caravans, in the hope that they would one day be delivered to his colleagues. There was little certainty of that happening. More problematic still are the situations in which knowledge is basically memorized and passed on by word of mouth (accompanied by somewhat incomplete papers intended to assist recall), because the circle of effective users typically remains confined to direct, personal contacts. Moreover, as that circle is widened, there is an increasing risk of the content becoming distorted in the course of oral transmission and successive copying. Only recurring communications back-and-forth among each of the pairs participating in such a network of transmission would operate to limit the propagation of "copying errors". The likelihood of that occurring, however, diminishes as the number of links in the human chain of communications increases.

Hence, there are physical limitations preventing expansion of the community of people who can harness new knowledge, and possibly further improve upon Rachid's design. Knowledge flows have existed throughout history, but, as a rule, they have been few and far between and relatively feeble. As we have seen, the principal exceptions were permitted by the maintenance of dense interpersonal communication networks, such as those that linked the Cistercian abbeys of medieval Europe. This has checked the development of cumulative momentum in the growth of the stock of reliable knowledge. To be sure, before the seventeenth century in the West, prevailing attitudes obstructed the widespread disclosure of "Nature's secrets" were perhaps more important than limitations of community technology in impeding effective cooperation in the pursuit of knowledge (see David, 1998, 2001c).

As for Rachel, let us say that she invented a small robot, working out the engineering details with the help of a computer-aided-design (CAD) program. Wishing to inform her community, she quickly produced the relevant documents and plans with the help of graphic design software. The files were then copied and despatched as email attachments to a list of selected addresses. Within seconds, they were received by dozens of laboratories throughout the world and hundreds of researchers could begin reproducing the knowledge and sending back their comments, criticisms and suggestions. Knowledge codification and transmission costs here were very low (i.e. Rachel's marginal costs of codifying and transmitting the knowledge in question, given the fixed infrastructure, and her training costs). So too were those of its reproduction. Indeed, this is the case when the invention itself remains within the framework of knowledge with which the community's members are familiar: the people receiving the file have "learned to learn" this kind of knowledge and the attached document provides a detailed learning programme.

A knowledge-intensive community is one wherein a large proportion of members is involved in the production and reproduction of knowledge. Therefore, it is likely that such a community constitutes a public (or semi-public) space where codification and dissemination costs have been radically reduced by the pre-existence of commonly employed concepts and terminological conventions; the existence of the latter further facilitates information and communication technologies to enhance the circulation of new knowledge.

\subsection{Knowledge-intensive communities and their "virtues"}

Rachid and Rachel are scientists, and, in the modern world scientific communities may be regarded as the specialized social organizations most thoroughly committed to 
the knowledge-based production activity if only because they are engaged in "the production of reliable knowledge by means of reliable knowledge". A majority of their members are, therefore motivated by the reward systems and social ethos reinforced by scientific community-specific institutions to disclose and share that knowledge (Dasgupta and David, 1994). Historically speaking, these scientific research communities, being concerned with the capture, storage, analysis, and integration of experimental and observational data, have been pioneers in the development and use of new information technologies.

Communities of programmers engaged in creating and improving so-called "open source" software resemble "open science" research communities in many of these aspects, and, like them, are not able to extract economic revenues directly from the sale of the new knowledge and information-goods that they create. They must find collateral, or ancillary sources of support (see Steinmuller (in this issue), Lakhani and von Hippel (2000) on "open source" communities).

Some business-to-business communities, however, also have modes of operation that share some of the same features. For example, general research consortia are club-like organisations, devoted to some collective technological goals which the members regard as jointly beneficial, and best pursued in a cooperative manner.

Doctors represent another instance of communities, in this case communities of professional specialization, that are undergoing a transition towards the higher frequency of peer-to-peer information transactions that is a key characteristic of the knowledge-based economy and, more generally, of the knowledge-society, Many doctors now document their new clinical knowledge and make it available to others through easily accessible electronic databases. Other practitioners then can draw on or add to that pool of information, thus enhancing the advance of evidence-based medicine.
Curiously enough, however, teachers at the elementary and secondary level, on the other hand, do not fit the template of the modern knowledge-based communities, even though they make intensive use of knowledge. There may be a massive amount of innovation going on as individual instructors strive to find solutions to their teaching problems, but, perhaps because those problems involve working with "unstandardized materials", i.e. their students, relatively few of those pedagogical innovations are passed on to, and shared by the rest of the community (Hargreaves, 2000).

Communities characterized by all three of the aforementioned components (extensive knowledge creation and reproduction, mechanisms for exchanging and disseminating the resulting knowledge and an intensive use of new information technologies) tend to be fundamentally geared to knowledge-driven production. As such, they display a certain number of "virtues":

- knowledge enhancement is boosted by a host of opportunities for recombination, transposition and synergy;

- a large share of the knowledge base is codified, which leads to greater storage and communication capacity and makes it possible to develop new cognitive approaches;

- quality control is guaranteed because members can each reproduce, test and criticize new knowledge;

- $\quad$ static efficiency is, as a rule, reinforced, meaning that because everyone has access to the knowledge produced, the same items will not end up being reinvented (while new knowledge can benefit from strong collective focus, collaborative experimentation and enhancement efforts);

- learning productivity is made greater by the fact that an individual can "learn to learn" 
through reproducing the knowledge of others;

- $\quad$ opportunities have emerged for the spatial reorganization of activities and the creation of virtual communities as it has become less expensive to move knowledge than people.

Is there an optimum size of knowledge-intensive community? From an empirical point of view, sizes will be seen to vary greatly between the global community of high energy particle physicists (comprising several thousand members) and a tiny community of aeronautical engineers working on a particular problem in airfoil design, or consortia among teams of molecular geneticists seeking to identify and locate the gene for a heritable form of breast cancer. The potential for producing and reproducing knowledge will become greater as a community expands; but then so will the costs of data search, the risk of congestion and anonymity amongst members, which can, in turn, represent a source of acute problems of trust. Optimum size may be said to vary as data search and filtering technologies improve and new trust-building mechanisms are perfected (see below, section 5.4). But it also depends on the nature of exchanges (geared merely to accessing a knowledge base or stemming from intensive interactivity within the framework of a research project).

\subsection{Knowledge communities as agents of economic change}

Most knowledge communities cut across the boundaries of conventional organizations (businesses, research centres, public and government agencies, etc.) and members of the former are at the same time employed by the latter. So, the development of the knowledge economy has seen, inter alia, conventional organizations infiltrated by individuals whose continuing attachment to an "external" knowledge community makes them all the more valuable to the organizations that harbour them as regular employees. Examples of this phenomenon from the world of business include engineers belonging to different firms who exchange knowledge and "trade secrets" within the framework of a network operating by the rules of reciprocity (von Hippel, 1988b); scientists employed by large pharmaceutical companies who are encouraged to publish in scientific journals and retain strong links with their university-based scientific counterparts (Cockburn et al., 1998); cooperative projects among users of the same technology (e.g. software) who expect to make use of the improved technology in the work as employees of different, and even rival companies (Lakhani and von Hippel, 2000). By penetrating conventional organizations, these communities become agents of change for their industry, and, indeed, for the economy as a whole.

In every such situation, however, there is always a danger of problems arising due to conflicts between private-sector companies that regard new knowledge as their exclusive property, and knowledge communities to whom sharing knowledge is their raison d'etre. The knowledge community is a fragile structure in that it is based on informal rules (reciprocity, disclosure). So it can rapidly disintegrate when their members lose the ability or the dedication to follow those rules, and, instead seek to further their individual interests through non-cooperative action in the realm of markets.

\section{A few unanswered questions}

The foregoing formulation of a definition and analytical approach to the notion of "knowledge-based activities" still leaves a good many quite basic questions to be answered concerning the workings of the evolving knowledge-based economy.

\subsection{Does the knowledge-based economy demand specific skills and abilities?}

Are "new skills and abilities" required for integration into today's knowledge economy? If so, what are they? Are they really as new as some might like to make out? Beyond the levels of proficiency needed for the use of information technologies, there do appear to 
be a number of set requirements: teamwork, communication and learning skills. But these sorts of "soft skills" can hardly be described as new. Indeed, though sidelined during the age of Fordism, they have always, throughout history, been crucial to the development and well-being of individuals in the world of work.

Many experts underscore the importance of generic learning abilities (learning to learn, knowing what we do not know, being aware of the main forms of heuristic bias that can distort the power of reasoning). ${ }^{6}$ It is better to have a firm command of such abilities, they say, than to be able to master a specific repertoire of technical skills. The need to keep up with incessant change is essentially what drives employees to develop new kinds of skills and abilities. These go beyond the constant updating of technical knowledge, for they also pertain to the capacity to understand and anticipate change.

\subsection{Returning market work to the home?}

Given how efficiently knowledge can travel when reduced to information, and the fact that the costs involved in moving people are still so high (and even rising with the growth in size of urban areas), one may well have grounds for believing that increasing numbers of people are going to be working at home now that the technological capacity is available for knowledge-sharing, remote access and teamwork, and organizing and coordinating tasks over wide areas. Does this herald the end of geography or, at the very least, of the influence of geographical distance over how activities are organized? Clearly, the influence of geographical distance is waning. Many different kinds of transactions now take place within the framework of location strategies "unconstrained by distance". And many customers have not the slightest idea where (geographically speaking) their transaction is being processed.

But whether or not this marks a trend of work returning to the home is rather less clear. Historical perspectives are still too sketchy to ascertain whether there really is "some tendency for the pendulum to start swinging back" (Mokyr, 2000), thus ending the centuries-long development of a factory system that has compelled workers in industry then services, trade and education to commute to work. ${ }^{8}$ The costs involved, though impossible to quantify, have certainly been huge. Cairncross (1997) suggests that in "half a century's time it may well seem extraordinary that millions of people once trooped from one building (their home) to another (their office) each morning, only to reverse the procedure each evening... Commuting wastes time and building capacity. One building - the home - stands empty all day; another - the office - stands empty all night. All this might strike our grandchildren as bizarre". Mokyr (2000) makes a sound case for considering some development of a home-production economy in light of the fact that it costs less to transport knowledge than people. Such developments, however, are likely to continue being impeded by all manner of apathy for some time to come. Which leaves much to be done as regards the redesigning of space in line with the opportunities offered by the knowledge economy.

Furthermore, many activities cannot be coordinated by virtual means alone.' The emulation and spontaneity generated by physical presence and social groupings often remain crucial. Likewise, direct face-to-face exchanges are important when they enable other forms of sensory perception to be stimulated apart from those used within the framework of electronic interaction. For many individuals, it is the personal interactions of the workplace, the stimulus provided by a change in environment from one's domestic habitat, that makes work enjoyable; futuristic scenarios depicting the joys of tele-working from one's home-office often are expressions of solitary authors, impatient with the intrusions of the world and people about them.

On the whole, individuals now have far more room to choose between working at home (and cutting commuting costs) and travelling to the collective workplace (to benefit from 
the advantages of interacting with a "real" group), but the question remains as to the extent that this option will prove attractive.

\section{The challenges}

The profound transformations that we have been examining are neither automatic and inevitable, nor will the results of the changes underway necessarily turn out to be universally beneficial. It is therefore important now to consider six major issues that our societies need to address in order to ensure a fuller realisation of the potentials of the knowledge economy.

\subsection{Access to information and to knowledge bases}

Our community-based approach has the virtue of showing that access to the knowledge economy is still highly limited and that there are great disparities between countries and social groups.

Clearly, the frequently distinction drawn between 'information society 'haves' and "have-nots" is overly simplified, as is the notion that there has emerged a "digital divide" that can and should be overcome by providing universal technical access to the Internet. Telecommunications access undoubtedly is a relevant consideration, given that more than two-thirds of the world's people today do not have the advantage of simple telephone connections, let alone computers and links to Internet service providers. Yet, the more difficult and in a sense more fundamental problems are not simply those of providing greater technological access to information streams. Rather, they involve furnishing people with the cognitive capacities and intellectual frameworks than enable humans to interpret, select and utilise information in ways that augment their capabilities to control and enhance the material circumstances and qualities of their existence.

One may say, then, that one of the respects in which "knowledge is power" reflects the fact that knowledge access is essential for meaningful information access. The relationship between human knowledge and information is reflexive, however; the formation of an individual's knowledge beyond the acquisition of understandings derived from personal experience is enormously abetted by receiving interpretable (decodable) information that encapsulates the shared learning of others. To put the point plainly, the nature of the content that is readily available for distribution is critically important. Access to channels of communication that are transmitting information of certain, capability-building kinds can play an instrumental part in accelerating the acquisition of the human cognitive skills that will impart enhanced relevance and greater value (utility) to the other information streams which also may by carried through those same channels.

Returning to the simpler issue of providing universal telecommunications access, for the moment, it is important to acknowledge how large a gap exists between reality and the evocative idea that because we all share the planet, humankind belong to "a global village" (UNDP, 1999). On the one hand, information infrastructure in some countries is so poor that "planet Internet" would appear to belong to altogether another galaxy. As many as 133 developing countries have asked the United Nations to maintain radio stations and other traditional media as a means of disseminating information, because use of the Internet alone would exclude many people from access to information flows.

Participation in knowledge-based economies, on the other hand, stems from intangible-capital investments in educational effort on the part of teachers and students, efforts directed to forming the basic skills and abilities (reading and writing) that text-based cultures require. Claims that a technological leap would enable a society to bypass certain stages in the development of knowledge infrastructures should be taken with a pinch of salt. Could e-books ever compensate for the lack of paper text-books for elementary school instruction? Can a civilization be rid itself of the disabilities of illiteracy through 
the widespead application of audio-visual media? Hardly. Post-literacy does not mean a return to illiteracy. It may be enjoyable and in some instances highly efficient for people to exchange information imparted by pictures, but, until a richer and standardised pictorial vocabulary is created, increasing reliance upon non-textual communications eventually will restrict the cognitive progress produced by more complex (codified) representations of knowledge (section 2.2).

That said, our community-based approach does provide a good many pointers and grounds for hope. Some scientific communities in the developing world are close to meeting the conditions to be able to participate more fully in the discovery and creation of new knowledge, rather than remaining trapped behind the frontiers of research and therefore unable to direct its advance toward the solutions of problems that have pressing relevance in their own societies. In their case, then, the problem really is one of becoming extensively equipped with high-quality information infrastructures of a sort that the researchers (many of whom trained abroad) already are capable of using.

Some of the problems of access to the large-scale and very costly research facilities in the natural sciences - of a sort that only the economically developed countries can afford, often through cooperative undertakings -now may be overcome by means of high-speed telecommunications. ${ }^{11}$ The latter permit remote access to observational instruments and mass data-transport for subsequent analysis, and the cost of providing the necessary bandwidth typically is much lower than that of constructing the facilities, even if the technical capability to build these existed in the developing country.

While "moving the data" is thus part of the solution, the international movement of scientific personnel gives rise to some significant problems for the developing countries. These are the losses of research and future teaching talent that may occur so-called scientific and engineering brain drains." As long as the viability of the developed countries' systems continues rely upon talented students abroad as the means of overcoming shortages of young people seeking advanced scientific training, they will pursue selectively liberal immigration policies that developing-country scientists find hard to resist; and communities will not be formed in their home land. ${ }^{12}$

The development of dynamic scientific communities does, of course, hinge on a number of other factors. ${ }^{13}$ But all the means are in place to bring an end to the "relentless pursuit of instruments of knowledge" for scientists working in developing countries. Other professional communities - doctors, teachers, urban planners and architects - also represent focal points where the key components of the knowledge-based community should gradually be deployed. Finally, Arora, et al. (this issue) stress the virtues of the technology markets as development tools whenever they help to drastically reduce the cost of access to technological know-how.

\subsection{Uneven development of knowledge from one sector to the next}

Unequal access to pertinent knowledge bases may well constitute an important condition underlying perceptible differences in the success with which different areas of endeavor are pursued within the same society, and the pace at which productivity advances in different sectors of the economy during a given historical epoch. In the nineteenth century, for example, even in the more developed high income economies, the improvement of agricultural productivity lagged behind that in industry in good part because the relevant knowledge base in plant and animal biology and soil chemistry was comparatively narrower, and less dynamic, than was the case in mechanics and inorganic chemistry. That situation was largely transformed by the second half of the twentieth century, as is testified to by the successes of "the Green Revolution" brought by new plant varieties, and the acceleration of agricultural productivity growth rates in the advanced economies to parity with those in their manufacturing sectors. 
Today it remains astonishing to observe the contrast between fields of economic activity where improvements in practice are closely reflecting rapid advances in human knowledge -- such as is the case for information technologies, transportation, and certain areas of medical care (surgery and drug therapy) -- and other areas where the state of knowledge appears to be far more constraining. Do people today know how to teach, plan cities, avoid the ravages of war, or perform string quartets any better than they did in the nineteenth century? Probably not to any noticeable extent. The fact is that knowledge is not being developed to the same degree in every sector.

In some measure this is attributable to the failure of mechanisms that would otherwise properly gauge the intensity of each of the items forming the array of society's wants, in the way that markets gauge the intensity of demands for the array of privately consumed commodities; thereby generating price signals which stimulate profit-motivated efforts to satisfy those wants. The combatants in a military conflict generate demands for weapons, to which arms merchants hasten to respond; the civilian populations that, as a result are likely to be "collaterally damaged" are not so readily able to generate "a market for inoperable weapons." Analogously, albeit less dramatically, the same point is made by observing that pharmaceutical companies respond to the large market demand for new drugs to treat ulcers and hypertension, rather than investing $\mathrm{R} \& \mathrm{D}$ on improving the availability of drugs for the victims of malaria and other tropical diseases that ravage poor countries.

Nevertheless, differences in the ability to focus demand do not provide a complete explanation. It is equally important to acknowledge that the uneven state of the accessible knowledge may arise from the fact that the capabilities for supply to respond to perceived wants are not everywhere the same. The sectors where knowledge creation has occurred at an extremely rapid pace are those in which the interrelationships between science and technology are especially close and intense. These are the sectors capable of carrying out controlled experiments and thoroughly testing results while maintaining constant liaison and feedback between the various stages of experimentation and application. Besides, technological advances generate better scientific instruments, which in turn help to improve experimentation methods. The interlinkages between "science-enlightened technology" and "technology-equipped science" provide the basis for the rapid development of knowledge in some areas. It is a model that involves heavy investment in off-line experimental research activities and large-scale knowledge codification so that interactions between science and technology can be sustained by a standardized and systematic knowledge system.

Many sectors visibly fail to meet these conditions for rapid progress. In the field of education, for instance, science does not much "enlighten" the art of teaching. It can hardly be said to play a very strong role as a factor enabling the direct production of systematic knowledge which translates into "programmes that work" in the classroom and lecture theatre. Education is not a field that lends itself well to experimentation: what works with a pilot school may prove hard to replicate elsewhere. Part of the problem is that experimental approaches are impossible to describe in precise enough detail to be sure that they really are being replicated (Nelson, 2000). Education also constitutes a realm where knowledge is little codified. There is no equivalent in teaching to the kinds of reference books and documents used by doctors, lawyers or engineers. So young teachers begin their careers without the help of those "sets of codified instructions". As a rule, the profession of teaching is not organised to keep practitioners informed of alternative approaches and solutions tested by others; instead they proceed by intuition and imitation of recognised practices in the repertoire of "master teachers". There are only weakly developed mechanisms whereby communities of educational practitioners collectively can capture and benefit from the individual discoveries made by their members. Opportunities for regular 
knowledge exchanges between educational researchers and teachers are few and far between (Hargreaves, 2000).

A good number of sectors not benefiting from the "science-enlightened technology" model thus find themselves confronted by the question of how they can enhance knowledge at similar speeds to the science-based sectors. Instead of attempting to export that model to sectors where it is ill-suited, one would be better off devising a role for science in contexts where the bulk of innovation stems from practical experience; a role geared not just to supplying "tools that work", but to developing a methodology for documenting, assessing and promoting practice-based innovations.

The success of the "science-enlightened technology" model has obscured the fact that there are other ways in which science can interrelate with technology; and that developing them can help to improve the advancement of knowledge in some sectors.

5.3 To protect intellectual property rights or the public domain of knowledge ?

The past two decades have witnessed growing efforts to assert and enforce intellectual property rights over scientific and technological knowledge through the use of patents, copyrights, and other, more novel forms of legal protection. (The latter include the special legislation introduced in the US in 1980 to extend copyright protection to the "mask work" for photo-lithographic reproduction of very large microelectronic circuits on silicon wafer, and the European Union's protection of databases by new national statutes implementing an EC Directive issued in 1996.) These developments have coincided with two other trends that, similarly, have tended to expand the sphere of private control over access to knowledge, at the expense of the public knowledge domain.

One trend has been the rising tide of patenting activity by universities, especially in the areas of bio-technology, pharmaceuticals, medical devices and software. This movement started in the US, where it received impetus under the 1980 Bayh-Dole Act (1980) that permitted patent applications to be filed for discoveries and inventions issuing from research projects that were funded by the federal government, but is has since spread internationally, being reinforced by the efforts in other countries to foster closer research collaboration between universities and public research institutes, on the one hand, and private industry on the other. The other trend has seen a concerted effort by all parties to secure copyright protection for the electronic reproduction and distribution of information, in part to exploit the opportunities created by electronic publishing, and in part to protect existing copyright assets from the competition that would be posed by very cheap reproduction of information in digital form over electronic networks.

The sudden upsurge of enthusiasm for expanding the private property rights over information has given rise to a rather paradoxical situation (Foray, 1999). The technological conditions (codification and low-cost transmission) may be right for individuals to be able to enjoy instant and unfettered access to new knowledge, but a proliferation of intellectual property rights inhibits access to such information in areas (basic research in general, the life sciences, software) where new knowledge had remained largely in the public domain. Thus, it may be said that individuals and firms today are striving to create artificial scarcities - by achieving legally sanctioned monopolies of the use of information -- in fields where abundance naturally prevails, thus giving rise to an enormous amount of waste.

To understand the economics of intellectual property, and thus the irony of this situation, one has to start from the observation that knowledge is not like any other kind of good, and certainly does not resemble conventional commodities of the sort that are widely traded in markets. Intellectual property cannot be placed on an equal footing with physical property, for the simple reason that 
knowledge and information possess a specific characteristic that economists refer to as "non-rival in use": the same idea and its expression may be used repeatedly, and concurrently by many people, without being thereby "depleted." This contrasts with the properties of ordinary "commodities" that are consumed: if Marie eats the last slice of cake in the kitchen, that piece cannot also be consumed by Camille; whereas, both girls may read the same novel either simultaneously or sequentially, and in so doing they will not have rendered the story any the less available for others to enjoy.

The allocation of property rights in the case of information-goods does not attempt to confer a right of exclusive possession, as do property laws governing tangible goods such as land. Indeed, to claim a right of possession one must be able to describe the thing that is owned, but no sooner do you describe your idea to another person than their mind comes into (non-exclusive) possession of it; only by keeping the information secret can you possess it exclusively.

What the creation and assigning intellectual property rights does, then is to convey a monopoly right to the beneficial economic exploitation of an idea (in the case of patent rights) or of a particular expression of an idea (in the case of copyright) that has been disclosed, rather than being kept secret. This device allows the organisation of market exchanges of "exploitation rights," which, by assigning pecuniary value to commercially exploitable ideas, creates economic incentives for people to go on creating new ones, as well as finding new applications for old ones. By tending to allocate these rights to those who are prepared to pay the most for them, the workings of intellectual property markets also tends to prevent ideas from remaining in the exclusive (secret) possession of discoverers and inventors who might be quite uninterested in seeing their creations used to satisfy the wants and needs of other members of society.

Another potential economic problem that is addressed by instituting a system of intellectual property rights is the threat of unfair competition -- particularly the misappropriation of the benefits of someone else's expenditure of effort - which might otherwise destroy the provision of information-goods as a commercially viable activity. The nub of the problem here is that the cost of making a particular information good available to a second, third, or thousandth user are not significantly greater than those of making it available to the first one. When Théo listens to a piece of music, modern reproduction and transmission technologies will permit Quentin, Manon and millions of others to listen to the same piece without generating significant additional costs. The costs of the first copy of a compact disk (CD) are very great, compared to the cost of "burning" a second, third or millionth copy of that CD. Ever since the Gutenberg revolution, the technical advances that have lowered the costs of reproducing "encoded" material (text, images, sounds) also has permitted "pirates" to appropriate the contents of the first copy without bearing the expense of its development. Unchecked, this form of unfair condition could render unprofitable the investment entailed in obtaining that critical first copy.

Producers of ideas, texts, and other creative works (including graphic images and music) are subject to economic constraints, even when they do not invariably respond to variation in the incentives offered by the market. If they had no rights enabling them to derive income from the publication of their works, they might create less, and quite possibly be compelled to spend their time doing something entirely different but more lucrative. So, there is an important economic rationale for establishing intellectual property rights. A strong case also can be made for protecting such rights by the grant of patents and copyrights, especially as that way of providing market incentives for certain kinds of creative effort leaves the valuation of the intellectual production to be determined ex post, by the willingness of users to pay; it thereby avoids having society try to place a value on the creative work ex ante - as would be required under alternative incentive schemes, such as offering prospective authors and inventors prizes, or awarding 
individual procurement contracts for specified works.

But, the solution of establishing a monopoly right to exploit that "first copy" (the idea protected by the patent or the text protected by copyright), alas, turns out not to be a perfect one. The monopolist will raise the price of every copy above the negligible costs of its reproduction, and, as a result, there will be some potential users of the information good who will be excluded from enjoying it. The latter represents a waste of resources, referred to by economists as the "dead-weight burden of monopoly": some people's desires will remain unsatisfied even though they could have been fulfilled at virtually no additional cost. Economists as a rule abhor "waste," or "economic inefficiency," but they believe in and rather like the power of market incentives. Not surprisingly, then, the subject of intellectual property policies has proved vexatious for the economics profession, as it presents numerous situations in which the effort to limit unfair competition and preserve incentives for innovation demonstrably results in a socially inefficient allocation of resources.

There is not much empirical evidence as to how altering the legal conditions and terms of intellectual property rights translates into change in the overall strength of economic incentives for the producers, or about the effectiveness of bigger incentives in eliciting creative results; nor is it a straightforward matter to determine the way in which holders of a particular form of intellectual property right would choose to exploit it, and the consequent magnitude of the resultant social losses in economic welfare ("the dead-weight burden"). Without reliable quantitative evidence of that kind, obviously, it is hard to decide in which direction to alter the prevailing policy regime in order to move towards the notional optimum for any particular market.
The difficulties of arriving at "scientific closure" on such matters, combined with conflicts of economic interests over the distribution of the benefits of new knowledge, quite understandably, have sustained a long history of intense debate in this area. In each era of history new developments affecting the generation, or the distribution of knowledge, give rise to a revival of these fundamental questions in new guises. Today, the "hot issues" arise from questions concerning the desirability of (a) curtailing patent monopolists' rights by letting governments impose compulsory licensing of the local manufacture of certain pharmaceutical products, or of some medical devices; (b) providing those engaged in non-commercial scientific research and teaching with automatic "fair use" exemptions from the force of intellectual law; (c) permitting purchasers of copyright protected CD's to freely share music tracks with others by means of peer-to-peer distribution over the Internet.

There is no easy general solution to this class of economic problems, and useful answers to the basic questions raised (are new rights that would better address the new circumstances required, and, if so, what form should they take?) will vary from one case, area or situation to the next. Most economic and legal analysis favours protecting broad classes of intellectual works, rather than very specific forms that are more likely to be rendered economically obsolete. But having flexible legal concepts which are meant to be applied in novel situations creates added uncertainties for innovators. There is likely to be a protracted period of waiting, and struggling to have the courts settle upon an interpretation of the law that is sufficiently predictable in its specific applications to provide a reliable guide for commercial decision-making.

Another general principle that finds widely expressed approval is that of harmonising intellectual property rights institutions internationally, so that arbitrary, inherited legal differences among national entities do 
not interpose barriers to the utilisation of the global knowledge base in science and technology. The catch in this, however, is that harmonisation rarely is a neutral procedure. Representatives of polities usually are loathe to cede property rights which their constituents already possess, and, consequently, programs of "harmonisation" turn out to impart an unwarranted global bias towards expanding the range of property rights that will be recognised and raising the strength of the protections afforded.

A more tenable broad policy position on this contested terrain may be derived from the recognition that the generation of further knowledge is among the major important uses of new knowledge, and, at the same time, there are enormous uncertainties surrounding the nature and timing of the subsequent advances that will stem from any particular breakthough. This is especially true of fields where new discoveries and inventions tend more readily to recombine in a multiplicity of ways that generate further novelties. A reasonably clear policy implication follows from this, and from the additional observation that although we will seldom be able to predict the details and future social value attaching the sequelae of a specific advance in knowledge, it is far more certain that there will be a greater flow of entailed discoveries if the knowledge upon which they rest remains more accessible and widely distributed. Therefore, rather than concentrating on raising the inducements to make "hard-to-predict" fundamental breakthroughs, it will be better to design intellectual property regimes in ways that permit non-collusive pooling and cross-licensing. As a practical matter, this consideration generally would call for raising the novelty requirements for patents, awarding protection for narrower claims, requiring renewals with increasing fees, and other, related measures. All of these steps would encourage entry into the process of generating further knowledge by utilising the breakthroughs that have occurred and been adequately disclosed (see David and Foray, 1996).
The import of this is to strictly limit the scope of grants of monopoly rights over research tools and techniques, curtailing the freedom of the rights-holders levy whatever "tax" they wished upon others who might use such inventions and discoveries in order to generate still further additions to the knowledge base. Collective knowledge enhancement is thwarted when discoveries cannot be freely commented upon, tested by replication, elaborated upon and recombined by others. Putting this in other words, intellectual property regimes designed to make it easier for many to "see farther by standing on the shoulders of giants" would appear likely to be more fruitful than a strategy which render those shoulders less easily mounted by others, in the hope that this would stimulate the growth of more, and taller "giants."

The extension of monopoly rights over the application of particular research tools in the life sciences -- techniques such as PCR (polymerase chain reaction) and monoclonal antibodies, new bioinformatic databases and search engines, as well as generic information about the structure of genetic material and the way that these govern the production of proteins - is coming to be seen as especially problematic. The issuing of such patents may indeed be responsible for stimulating more commercially oriented $\mathrm{R} \& \mathrm{D}$ investment by pharmaceutical companies, and others who look forward to selling them access to new information. Yet, intellectual property protection in this sphere is likely to impose heavy dynamic welfare losses on society. It will do by impeding access to existing information, or by increasing the wasteage of resources in functionally duplicative research aimed at avoiding patent licensing charges. This raises the cost not simply of research directed toward producing a specific new product(e.g., diagnostic test kits for a particular class of genetically transmitted conditions), but, also of exploratory research that may enable the future creation of many applications, including those that still are undreamt of. To use the evocative phrasing of a leading European scientist, cooperatively assembled bioinformatic databases are permitting researchers to make important discoveries in the course of "unplanned 
journeys through information space." If that space becomes filled by a thicket of property rights, then those voyages of discovery will become more troublesome and more expensive to undertake, unanticipated discoveries will become less frequent, and the rate of expansion of the knowledge base is likely to slow.

Popular wisdom maintains that "good fences make good neighbours". This may apply in the case of two farmers with adjacent fields one growing crops and the other grazing cattle - or gold diggers excavating neighbouring concessions. But unlike land, forage or other kinds of exhaustible resources, knowledge is not depleted by use for consumption; data-sets are not subject to being "over-grazed", but instead are likely to be enriched and rendered more accurate the more that researchers are allowed to comb through them (David, 2001).

The issues just examined are entangled with other, difficult problems concerning the institutional (as distinct from the technological) determinants of human beings ability to enhance their "capabilities" by finding and making use of existing repositories of knowledge and sources of information (Foray and Kazancigil, 1999). There are special problems of access to scientific and technological knowledge relevant to developing countries; ${ }^{12}$ of what is means to maintain that every individual has a right to benefit from the collective advance of human knowledge affecting such fundamental, capability enhancing conditions as health and education. ${ }^{13}$

A delicate attempt at regaining a better balance between protection of the public domain of knowledge from further encroachments by the domain of private property rights, at least in regard to some sectors where services are recognised to profoundly effect human "well-being" (health, education). The notion of a universal right to health appears to have the "strength" to countervail against the national and international campaigns led by pharmaceutical companies to secure intellectual property owners the right to unregulated exploitation of their patents (cf.
Cassier, this issue). But, one must not be deluded into supposing that appeals to principles of equity alone will be sufficient in deciding such contests in the area of political economy.

\subsection{New problems of trust?}

Fraudulent behaviour, forgery and pretence have obviously not been spawned all of a sudden by the virtual world. Questions concerning the original and the copy (Eco, 1992), not to mention the evaluation of goods that are the object of commercial transactions, have given rise to the problem of trust and have highlighted how crucial trust-building mechanisms are to the functioning of markets and communities since the beginning of time. But the development of virtual relations has given the trust issue a new edge. What is at stake here is the entire range of mechanisms that will facilitate interpersonal and inter-organizational transactions, given the new conditions for knowledge transactions and exchanges: increasing specialization, increasingly asymmetrical distribution of information and assessment capabilities, ever-greater anonymity among interlocutors and ever-more opportunities for forgery of identity. Clearly, new methods need to be devised to "certify" the knowledge circulating on the Internet within a context where inputs are no longer subject to control (unlike the knowledge disseminated by scientific journals, for example, whose quality and reliability are validated through the peer review process).

\subsection{A society bereft of memory}

Today's younger generations might never experience the emotions aroused on rediscovering old toys or books in the attic and picking them up to find that they still work. Future machines may never be able to bring back to life the equivalent of our elders' wooden horses and toy soldiers: the playstation, earlier versions of which are already impossible to use on the latest computers. Our societies are confronted by an almost paradoxical situation whereby we have never before had such powerful storage 
and memorization technologies at our disposal, yet memory itself appears to be in danger. Two problems are beginning to emerge.

First, with information technologies, we are not saving documents but sets of instructions that need to be interpreted and managed by the right hardware and software. So any lack of attention paid to the complementary components of a codified knowledge system (continuity of languages, keeping programmes that enable access to older files) runs the risk of irremediably altering society's overall memory.

Second, given the exponential growth of all manner of documents, does it all really need to be kept? If not, then what does? On what medium (electronic, paper)? The unit costs of short-term storage and data retrieval may have fallen, but significant problems remain with respect to memorizing, filing and accessing old documents. The new electronic media for storage are not so stable, indeed, they are unstable in comparison with the low-sulfite rag paper on which good books have long been printed. Furthermore, the artifical languages used to encode information for computer processing also is comparatively less stable, in that it is more likely to suddenly become obsolete, requiring the corpus of stored information to be periodically "migrated" to a new code that new programs are able to read. This has made "storage" of information in the digital age less a matter of archiving than a process of recurring renewal, a cultural task for which literate societies turns out not to be well-prepared.

\subsection{Fragmented knowledge: how can it be put back together again?}

There is a natural tendency for knowledge to fragment as it becomes subject to more in-depth division and dispersion. The division of knowledge stems from divisions of labour and increasing specialization. Its dispersion is the product of increasingly diffuse sources of innovation. The result is an extremely fragmented knowledge base, which makes it difficult to form a broad and integrated view of things. This can have disastrous consequences. At the level of global policy-making, knowledge that can help resolve a particular problem may exist without being "visible". It can go unnoticed by the decision-maker. Knowledge of the greenhouse effect, for instance, has been in the public domain since 1886 thanks to the study by Svente Arrenhuis, but failed to capture the attention of the political system for another hundred years. There is a big difference between the existence of knowledge in some place or the other and its availability to the right people in the right place at the right time. It amounts to a matter of knowing how to integrate and organize fragmented, scattered and thinly-spread knowledge. $^{16}$

The famous economist, Alfred Marshall, raised basically the same question, albeit with respect to industrial activities: how can one organize and coordinate highly specialized activities within a context marked by an extreme social division of labour? The answer, according to Marshall, lay in two main factors: a reduction in transport costs and local concentrations of activity clusters, with each locality creating the right conditions for integrating knowledge (Loasby, 1989).

So the whole question revolves around the capacity of the new information technologies to enable better integration of knowledge through helping bring down the cost of transporting it and paving the way for local concentrations of virtual activities.

The new technologies, under certain conditions (see section 2) clearly do favour the low-cost transmission of knowledge and the creation of virtual communities. But the maintenance of human organizations in which incompletely codified knowledge resides poses a variety of socially and politically delicate challenges, involving the establishment of procedural authority to decide contested cognitive questions and stablize the knowledge held by the community, as well as to recruit new members and inculcate in them the cooperative mores that suppress destructive 
opportunistic behaviors (Steinmueller, 2001). Evidently, managing a social repository of knowledge is not the same thing as managing a library or an archive. Yet, much of the history of civilisation, from the dawn of literacy onwards, has focused attention and physical resources upon the evolutionary elaboration of archiving techniques and bought a corresponding waning of systematic commitment of investment in alternative modes of maintaining the continuity of memory in dynamic communities.

That is not the only problem, however: some researchers, however, argue that the use of powerful communication technologies such as the Internet may promote uniformity to the detriment of diversity (Van Alstyne and Brynjolfsson, 1996). The time spent in on-line exchanges with members of one's own, pre-selected community leaves less time available for actual encounters with a wide-ranging variety of people: if a physicist is enabled to concentrate upon exchanging email and electronic pre-prints with other physicists around the world who are working in her specialized subject area - as indeed researchers today generally are - they are likely to devote less time, and be less receptive to new ways of looking at the world to which they would be exposed by chance meetings, and lunch-time conversations with colleagues who work in other disciplinary fields. Facilitating the voluntary construction of highly homogeneous social networks of scientific (or other, say, political) communication therefore allows individuals to filter the potentially overwhelming flow of information. But the result may be the tendency of over-filtering, which eliminates the diversity of knowledge and that circulates, and thus diminishes the frequency of radically new ideas. In this regard, even a journey through the stacks of a real library can be more fruitful than a trip through today's distributed virtual archives, because it seems difficult to use the available "search engines" to efficiently emulate the mixture of predictable and surprising discoveries that typically result from a physical shelf-search of an extensive library collection. New technologies are not automatically going to resolve the issue of knowledge integration.
What really needs to be done is to establish and develop interdisciplinary communities made up of a heterogeneous range of members. In such cases, the sound "Marshallian" properties of information technologies really can serve to support the integration of knowledge.

\section{From the knowledge-based economy to the knowledge-based society}

The knowledge economy's growth into the knowledge society hinges on the proliferation of knowledge-intensive communities. These communities are basically linked to scientific, technical and some business professions or projects. As has been said, they are characterized by their strong knowledge production and reproduction capabilities, a public or semi-public space for learning and exchange and, the intensive use of information technologies. To function effectively, they must have overcome many, if not all of the challenges that this review has identified. Only when increasing numbers of communities displaying those very characteristics are formed across a wide array of cognitive fields, when professional experts, ordinary users of information, and uninitiated students are brought together by their shared interest in a given subject, will "the knowledge society" become a reality rather than a vison of a possible future. 


\section{Notes}

1. The French language offers a distinction between "savoir" and "connaissance" that has no real equivalent in English, though it can be conveyed by adding the qualifier "reliable". Reliable knowledge ("savoir") means certified, robust knowledge that has been legitimized by some institutional mechanism (be it scientific peer review or collective memory and belief systems). Other forms of knowledge ("connaissance") also enable action (knowing how to do the gardening, DIY) but have not been put through the same tests as certified knowledge. What separates the two has less to do with a contrast between the scientific and non-scientific than whether or not the knowledge has been subjected to institutional testing: "gardening knowledge" is reliable, wide-ranging and relatively decontextualized, but each gardener has his or her own local (and locality-specific) knowledge. Yet the knowledge-based economy does not preclude either form, meaning that it is not geared solely to the formal production of "reliable knowledge".

2. The article by Hatchuel, et al. (this issue) provides useful insight into the new knowledge management methods used by companies within the context of "intensive innovation-based capitalism".

3. The article by Rabeharisoa and Callon (this issue) is entirely devoted to this point.

4. This is an important distinction, the implications of which are examined in greater detail by Steinmueller, by Forero Pineda and Salazar, and by Hansson and Lam (all in this issue).

5. On the concept of "tacit knowledge" and its recent uses in economics, see Cowan, David and Foray (2000), and other contributions accompanying this article in the same special issue of Industrial and Corporate Change, 9(2), Guest-edited by P. Cohendet and W. E. Steinmueller.

6. The concept of public (or semi-public) spaces for knowledge circulation is complex. Such spaces can include areas in which exclusive property rights cannot be granted, either "constitutionally" (as in the case of open science) or within the framework of organizations especially designed for the purpose (research networks and consortia where partners share their knowledge) and markets whose modi operandi are conducive to efficient knowledge dissemination (see the articles in this issue by Cassier and Arora, et al.).

7. This can happen when too much importance is attached to the latest information or too little attention is devoted to the size of sample selected to assess information. Another good example is be the familiarity heuristic (cf. Favereau, 1998).

8. See the article by Lam on the comparative analysis of the societal organizations underpinning the development of skills in the knowledge-based economy (this issue).

9. Some $65 \%$ of industrial workers in France were already working away from home by 1906 (Mokyr, 2000).

10. This point is more fully discussed by Feldman (this issue).

11. On large scale facilities for scientific research, the potentialities of electronic data networks, and international cooperation in "megascience" projects, see, e.g., Irvine (1997), esp. Chs. 28, 30.

12. Some authors call for the deployment of knowledge networks that involve the return of scientists and engineers (e.g. from California to Taiwan or certain parts of India). According to this "brain circulation" model, the latter return home highly trained and imbued with the entrepreneurial spirit of Silicon Valley. But it gives rise to other such problems as the isolation of the scientific elite from the rest of the population and the propagation of a single socio-economic model (Saxenian, 2001).

13. See the article by Forero Pineda and Salazar (this issue).

14. See the articles by Forero Pineda and Salazar, Sarmiento and Forero Pineda, and Arora, et al. (this issue).

15. See the article by Cassier (this issue).

16. See the article by Hansson on integrated knowledge within the context of public debate and decision-making processes (this issue). 


\section{References}

ABRAMOVITZ, M. and DAVID, P.A. 1996. "Technological Change and the Rise of Intangible Investments: the US Economy's Growth-path in the Twentieth Century", in D. Foray and B. A. Lundvall, (eds.), Employment and Growth in the Knowledge-based Economy, OECD Documents, Paris: OECD. ABRAMOVITZ, M. and DAVID, P. A. 2000. "American Macroeconomic Growth in the Era of Knowledge-Based Progress: The Long-Run Perspective," in S. L. Engerman and R. E. Gallman, eds., An Economic History of the United States: The Twentieth Century, Vol. 3, New York: Cambridge University Press, pp. 1-92.

CAIRNCROSS, F. 1997. The Death of Distance: How the Communications Revolution Will Change Our Lives, Boston: Harvard Business School Press.

COCKBURN, I., HENDERSON, R. and STERN, S. 1999. "The Diffusion of Science-driven Drug Discovery: Organizational Change in Pharmaceutical Research", NBER working paper, 7559, Cambridge, MA.

COWAN, R., DAVID, P. A., and FORAY, D., 2000. "The Explicit Economics of Knowledge Codification and Tacitness," Industrial and Corporate Change, 9(2): pp. 211-253.

DASGUPTA, P. and DAVID, P.A. 1994. "Towards a New Economics of Science", Research Policy, 23, pp. 487-521.

DAVID, P.A. 1990. "The Dynamo and the Computer: An Historical Perspective on the Modern Productivity Paradox", American Economic Review, 80 (2), May.

DAVID, P. A.,1998. "Common Agency Contracting and the Emergence of 'Open Science' Institutions," American Economic Review, 88(2), May 1998, pp. 15-21.

DAVID, P. A., 2000a. "Understanding Digital Technology's Evolution and the Path of Measured Productivity Growth: Present and Future in the Mirror of the Past", in E. Brynolfsson and B. Kahin, eds., Understanding the Digital Economy, Cambridge MA: MIT Press, pp. 49-95.

DAVID, P. A., 2000b. “ The Digital Technology Boomerang: New Intellectual
Property Rights Threaten Global 'Open

Science," [Presented to World Bank ABCDE-Europe 2000, Paris, 26-28 June.]

Available as

http://www-econ.stanford.edu/faculty/wor $\mathrm{kp} / \mathrm{swp} 00016 . \mathrm{html}$.

DAVID, P. A. 2001a. "Productivity Growth Prospects and the New Economy in Historical Perspective," European Investment Bank Papers, 6(1), Spring, pp 41-61.

DAVID, P. A. 2001b. "Digital Technologies, Research Collaborations and the Extension of Protection for Intellectual Property in Science: Will Building 'Good Fences’ Really Make 'Good Neighbours??', in IPR Aspects of Internet Collaborations [EUR 19456. Final Workshop Report for the European Commission DG Research, Directorate B-European Research Area: Structural Aspects], Brussels: European Commission, March, pp. 56-62.

DAVID, P. A. 2001c. "From Keeping Nature's Secrets to the Institutions of Open Science," Oxford Economic and Social History Discussion Papers, 23. July. DAVID, P. A. and FORAY, D., 1996. "Information Distribution and the Growth of Economically Valuable Knowledge: A Rationale for Technological Infrastructure Policies," in Technological Infrastructure Policy, M. Teubal et al., eds., Dordrecht and London: Kluwer Academic Publishers.

ECO, U. 1992. "The Original and the Copy", in F. Varela and J.P. Dupuy (eds.) Understanding Origins, Kluwer Academic Publishers.

FAVEREAU, O. 1998. "Notes sur la théorie de l'information à laquelle pourrait conduire l'économie des conventions", in P. Petit (ed.) L'Économie de l'Information, Paris: La Découverte.

FORAY, D. 1999. "Science, Technology and the Market", World Social Science Report, UNESCO Publishing/Elsevier.

FORAY, D. and KAZANCIGIL, A. 1999. Science, Economics and Democracy: Selected Issues, MOST, Discussion paper no. 42, UNESCO. GOODY, J. 1977. The Domestication of the Savage Mind, Cambridge University Press.

GORDON, R. 2000. "Does the 'New Economy' Measure up to the Great 
Inventions of the Past?", Journal of Economic Perspective.

HARGREAVES, D. 2000. "La production, le transfert et l'utilisation des connaissances professionnelles chez les enseignants et les médecins: une analyse comparative", in OECD, Société du Savoir et Gestion des Connaissances, Paris: OECD.

IRVINE, J., with MARTIN, B. et al., Eds.,1997. Equipping Science for the 21 ${ }^{\text {st }}$ Century, Cheltenham, Eng.: Edward Elgar.

LAKHANI, K. and VON HIPPEL, E. 2000. "How Open Source Software Works: Free User to User Assistance", MIT Sloan School, working paper 4117.

LOASBY, B. 1989. The Mind and Method of the Economist, London: Edward Elgar.

MOKYR, J. 2000. "The Rise and Fall of the Factory System: Technology, Firms, and Households Since the Industrial Revolution", Journal of Monetary Economics (forthcoming).

NELSON, R. 2000. "Les systèmes de savoir et d'innovation", in OECD, Société du Savoir et Gestion des Connaissances, Paris: OECD.

OECD 1999. L'économie fondée sur le savoir: des faits et des chiffres, Paris: OECD.

POLANYI, M. 1967. The Tacit Dimension, New York: Doubleday.

SAXENIAN, A. 2001. "The Bangalore Boom: From Brain Drain to Brain Circulation?", in KENNISTON, K. and D. KUMAR (eds.) Bridging the Digital Divide: Lessons from India, Bangalore: National Institute of Advanced Study (forthcoming).

STEINMUELLER, W.E. 2001. "Virtual Communities and the New Economy", in R. Mansell (ed.) Inside the Communication Revolution, Oxford University Press.

UNDP 1999. Human Development Report, United Nations Development Programme, Geneva.

VAN ALSTYNE, R. and BRYNJOLFSSON, E. 1996. "Could the Internet Balkanize Science?”, Science, vol. 274, 5292.

VON HIPPEL, E. 1988a. The Sources of

Innovation, Oxford University Press.

VON HIPPEL, E. 1988b "Trading Trade

Secrets”, Technology Review, February-March. 